RESEARCH ARTICLE

\title{
Multiutility Service Companies: A Complex Systems Model of Increasing Resource Efficiency
}

\author{
LIZ VARGA, MARGUERITE ROBINSON, AND PETER ALLEN \\ Complex Systems Research Centre (CSRC), School of Management (SoM), \\ Cranfield University, Cranfield, Bedfordshire MK43 OAL, United Kingdom
}

Received 10 December 2014; revised 10 April 2015; accepted 1 June 2015

\begin{abstract}
Domestic households account for a significant portion of energy consumption and carbon emissions in the United Kingdom. Gains in energy and resource efficiency are undermined by the continuing rise in consumption. A multiutility service company (MUSCo) could enable households to make efficiency improvements through energy technologies and demand management, thus reducing overall consumption. We present a system dynamics model for the domestic energy demand and supply system in the United Kingdom, in which MUSCos compete with traditional utility providers. The market transition toward a leasing contracted service is examined and various potential business models explored. () 2015 Wiley Periodicals, Inc. Complexity 000: 00-00, 2015
\end{abstract}

Key Words: energy efficiency; utilities; complex systems

\section{INTRODUCTION}

A lthough there continue to be large gains in energy and resource efficiency, overall energy consumption continues to grow: more consumption typically means progress, such as rising living standards, gains in health and welfare, and these lead to greater economic growth [1]. The

(C) 2015 The Authors. Complexity Published by Wiley Periodicals, Inc.

This is an open access article under the terms of the Creative Commons Attribution License, which permits use, distribution and reproduction in any medium, provided the original work is properly cited.

Correspondence to: Liz Varga, E-mail: liz.varga@cranfield.ac.uk progressive reduction worldwide in energy intensity (the ratio between consumption of primary energy and output of goods and services) is largely due to continual pressure to cut costs [2]. Further reductions in total energy usage could be achieved by cutting losses within the energy system, for example, in energy distribution [2], but we focus on potentially greater improvements in domestic energy efficiencies which ultimately reduce consumption while providing the same quality of domestic liveability. For the purposes of our investigation, the householder may experience a real reduction in energy bills, but this is likely to be marginal, and largely in respect of balancing continuous energy price rises with reduced energy consumption. Any significant real savings could result in undesirable rebound 
effects whereby the savings are spent on other energy consuming activities. In the transport sector, there is evidence that fuel efficiency savings cause a rebound effect, an increase in miles travelled, [Correction added on 3 August 2015, after first online publication: traveled changed to travelled] of between $10 \%$ and $30 \%$ [1], so our aim is not to simply reduce energy bills.

UK domestic energy consumption rose by $16 \%$ between 1970 and 2012. In the 1970s, few homes had central heating or owned the household appliances taken for granted today. During this period, there were fundamental changes in housing stock, an increase in insulation and draught proofing, a rise in more energy efficient heating systems shifting from coal to gas [2], all dampened by the growing number of lights and variety of domestic appliances. Also, the number of homes increased by two fifths, with a fall in the average number of people per household, and so the average household consumption per year has declined from 23,800 to $18,600 \mathrm{kWh}$ [3]. However, the number of households will increase by a fifth over the next quarter century creating concerns for energy consumption growth. Several drivers exist to improve the energy efficiency of the nation. They include: reducing environmental impact using nonpolluting, renewable resources [4] and improving the greenness of fossil fuel use [5]; reducing the cost of energy, through technological improvements [6], or by changing household behaviors (demand) [7] or by engaging in community level schemes to reduce per household resource usage through meso-scale energy solutions [8].

Domestic homes account for $29 \%$ of energy consumption [9] and more than a quarter of carbon dioxide emissions in the United Kingdom [3]. The government's Standard Assessment Procedure (SAP) is now widely used to measure the basic energy efficiency of homes. The average rating was just 43 in 2003 [10] reflecting that the housing stock is some of the oldest and most energy inefficient in the Western world. Energy efficiency improvements in previously inefficient homes are likely to lead to intentional increases in temperatures with the benefit of thermal comfort in exchange for energy cost savings [11]. Furthermore, technology efficiency ratings for domestic appliances are used as key marketing tools by technology retailers and some technologies can "automate" the behavioral habits of consumers in the home to reduce energy costs. Examples include, closing down of an appliance after $x$ minutes of lack of use, or energy nonuse/avoidance at peak times.

The [Correction added on 3 August 2015, after first online publication: principal changed to principle] principle of avoiding energy costs via energy efficiencies underlies the proposal here. But it is recommended as an alternative to the current domestic energy arrangements of traditional utility product supply companies and householder incentive schemes led by the government. A multi- utility service company or MUSCo can help enable households to make energy efficiencies via a rounded package of energy technologies and energy demand management. The MUSCo uses a new business model to improve energy efficiency through reduced resource use by both technological improvements and behavioral contracts with householders. The MUSCo profits through scale procurement of technological appliances and by assurances to energy suppliers of energy demand patterns thereby avoiding gate closure demand. Fringe benefits for the MUSCo could include householder penalties if they demand more energy than their contracts provide; and government incentives to support low emissions technologies helping to meet the Carbon Act. The householder is locked-in to the MUSCo for the term of contract and a revenue stream is assured.

There are several benefits to the householder. They are financially no worse off because their energy costs are lower (as the household is more efficient), their loan is tied to their property and the total of energy costs and loan repayment does not cost more than current energy bills. It is assumed that energy costs will continue to rise. Householders have not reduced their level of comfort and may have improved levels of comfort with indirect benefits to health and wellbeing. They also have efficient technological devices which can reduce demand for other resource use, such as water or heat. The household could not have acquired the technology as cheaply as the MUSCo and they have peace of mind because the MUSCo will lease it to the household and maintain it thereby ensuring it is in efficient working order.

In this article, we present a model for the transition of the residential household population toward a leasing contracted service. A population level perspective is adopted and individual household characteristics are not addressed in the current work. The importance of household heterogeneity in real-world social systems has been documented [12] and this individualistic behavior is examined in the service perspective paper in Ref. [13]. The current work suggests that there is a "win-win" to energy efficiency, which moves us toward sustainable consumption and the ability to live better by consuming less and reduce our impact on the environment in the process [14].

\section{THE MODEL}

The system we consider includes: people who live in various different types and sizes of house, comprising the "household"; the levels of efficiency in resource use (energy and water) of these households; traditional utility companies; and novel MUSCos. The importance of the MUSCo will be in its ability to hasten the transition to a more efficient residential housing sector, by reducing both resource usage and greenhouse gas emissions. In the United Kingdom, the SAP rating is expressed on a scale of 1-100 [15], 


\section{TABLE 1}

SAP Ratings and Bands. Source: [15]

\begin{tabular}{lc}
\hline Rating & Band \\
\hline $1-20$ & $\mathrm{G}$ \\
$21-38$ & $\mathrm{~F}$ \\
$39-54$ & $\mathrm{E}$ \\
$55-68$ & $\mathrm{D}$ \\
$69-80$ & $\mathrm{C}$ \\
$81-91$ & $\mathrm{~B}$ \\
$92-100$ & $\mathrm{~A}$ \\
\end{tabular}

with higher values indicating better performance. Based on this rating houses are assigned to one of seven bands, Table 1. To represent the energy performance of households in the model, we construct 11 discrete levels of energy efficiency, which represent mean efficiency percentages of $[0 \%, 10 \%, 20 \%, \cdots, 100 \%]$. This structure is used for computational convenience and could be mapped to the official SAP energy bands given in Table 1.

The market will be composed of independent households, who receive resources from traditional utility firms and are not tied into a contract. Two MUSCo-type firms are represented in the model, which we label $M_{2}$ and $M_{3}$. Initially, it is assumed that a small population of households have already upgraded their efficiency and switched to a
MUSCo. The initial household population consists of 28 million residential dwellings, $H_{\text {tot }}(0)=28 \times 10^{6}, 0.8 \%$ of which are signed to a MUSCo and are equally distributed between the two MUSCo firms and across all 11 efficiency levels. The three distinct household subpopulations will be denoted by $H^{k}(t)$ for $k=1,2,3$, representing independent households provided with utility products via traditional utility companies, those signed with $M_{2}$ and those signed with $M_{3}$, respectively, such that, at any time $t \geq 0$, we have

$$
H_{\text {Tot }}(t)=\sum_{k=1}^{3} H^{k}(t) .
$$

Households vary widely on their resource use efficiency and this is represented by distributing the initial household population across the range of efficiency bands, as shown in Figure 1. More formally, each household is designated an initial efficiency grade $i \in[0,1,2, \ldots, 10]$, representing the 11 efficiency percentage levels, and from which it can independently self-finance an upgrade or sign a contract with a MUSCo firm, such that the sum of households belonging to service provider $k$ at time $t$ is

$$
H^{k}(t)=\sum_{i=0}^{10} H_{i}^{k}(t), \quad \text { for } \quad k=1,2,3 .
$$

\subsection{The Traditional Utility Market}

Household dynamics evolve as a result of customers investing in a house improvement scheme that will reduce

\section{FIGURE 1}

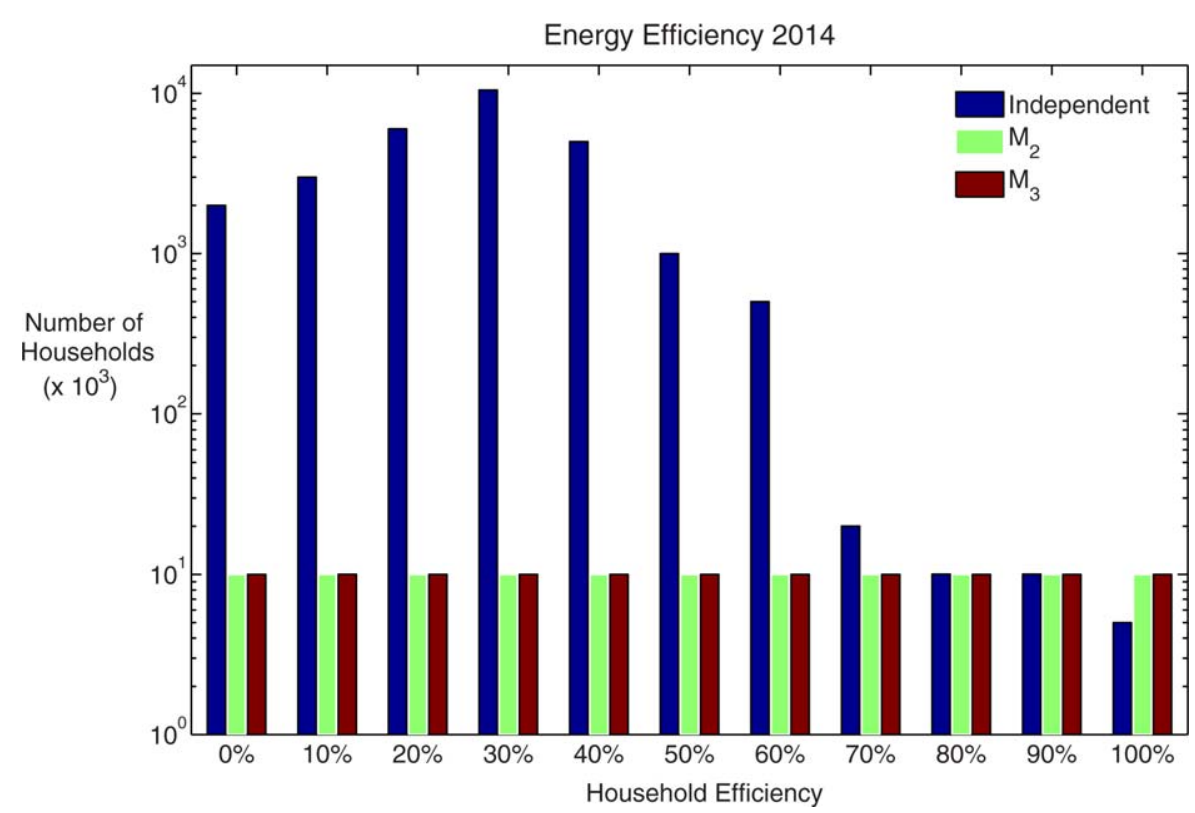

The initial energy efficiency distribution of households 


\section{FIGURE 2}

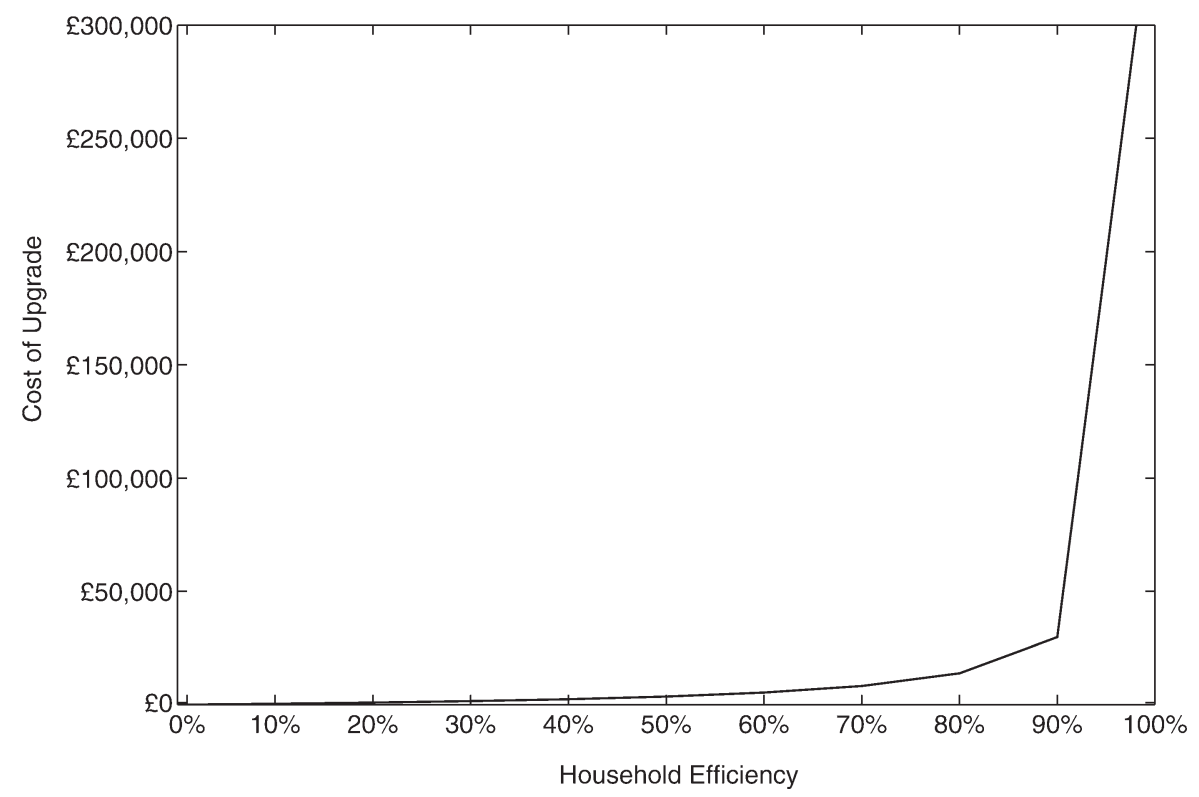

Nonlinear increase in household efficiency upgrade costs from $0 \%$, at a cost of $£ 400$ for the initial $10 \%$ upgrade.

resource use. This decision will reduce future consumption at a given fixed cost of improvement. The cost of improvement will be greater if the existing efficiency is already high. If the simple assumption is made that the difficulty and cost of improving the current efficiency increases with the level of efficiency already achieved, then each upgrade increase of $10 \%$ will sequentially cost more and more. For each $10 \%$ energy demand reduction (achieved by a $10 \%$ efficiency upgrade), the cost will lie in the improved insulation and domestic appliances that are needed to further optimize resource usage. It is assumed that this cost is determined by the formula

$$
\operatorname{Ins}_{j, i}=\operatorname{Ins}_{0} \frac{i-j}{(10-i)(10-j)+1},
$$

which represents a household upgrade from efficiency level $j$ to $i$. Thus, the cost of the first $10 \%$ upgrade (from $0 \%$ to $10 \%$ ) will satisfy $\mathrm{Ins}_{0,1}=\mathrm{Ins}_{0} / 91$. For example, consider a scenario where the initial $10 \%$ upgrade costs $£ 400$, then the cost of larger incremental upgrades from a base of $0 \%$ will increase as displayed in Figure 2, such that an improvement from $0 \%$ to $100 \%$ would cost in excess of $£ 300,000$. Each step of improvement yields a saving on the cost of consumption, but the cost of the extra insulation and appliances rises steeply. Thus, a household with $0 \%$ efficiency and average annual utility costs of $£ 2400$ could cut costs by $£ 240$ per year by investing $£ 400$, yielding a high return on investment of $60 \%$. Alternatively, consider the case of a household shifting from $60 \%$ to $70 \%$, then the return on investment would be approximately $9 \%$, which is less but still reasonably good. However, as the cost of energy rises the return on investment will also increase. For example, if the cost rose at 3\% per annum for 40 years, then it would cost approximately 3.5 times more, yielding a return on investment of over $25 \%$.

The dynamics of household improvement will be governed by the investment in better insulation and appliances that will give a return resulting from reduced energy costs. The model developed here will describe the decision of households to make an investment to improve their energy efficiency, using the economies resulting from reduced resource use to pay for it. Clearly, the higher energy costs are the more incentive there is to make efficiency improvements. Over the range of efficiency levels $0-100 \%$, the net benefit over a 10 year interval for a household increasing its energy efficiency from level $j$ to $i$ will be the percentage reduction of use times the energy cost, minus the cost of attaining that level of insulation, such that

$$
\text { Benefit }_{i, j}=P_{\mathrm{e}}(i-j)-\operatorname{Ins}_{j, i},
$$

where $P_{\mathrm{e}}(t)$ is the mean annual household energy costs at the present time. This expression yields a surface of benefit, representing the attraction of attaining a particular level of household improvement (\% efficiency), Figure 3. A household will be attracted to move from $j$ to $i$ if the net benefit is large, Table 2. It is assumed that this benefit impacts a household's attraction to a given improvement according to the following expression 


\section{TABLE 2}

The Net Benefit, Over a 10 Year Period, of Upgrading from Efficiency Level $j$ to Efficiency Level $i$ in a Traditional Utility Household. Values Shown are for an Annual Energy Cost of $£ 2000$ and an Insulation/Appliance Cost of $£ 300$ for the First $10 \%$ Upgrade

\begin{tabular}{|c|c|c|c|c|c|c|c|c|c|c|c|c|}
\hline & & \multicolumn{11}{|c|}{$i$} \\
\hline & & 0 & 1 & 2 & 3 & 4 & 5 & 6 & 7 & 8 & 9 & 10 \\
\hline \multirow[t]{11}{*}{$j$} & 0 & $£ 0$ & $£ 1,700$ & $£ 3,325$ & $£ 4,846$ & $£ 6,209$ & $£ 7,323$ & $£ 8,004$ & $£ 7,835$ & $£ 5,600$ & $-£ 4,336$ & $-£ 253,000$ \\
\hline & 1 & $£ 0$ & $£ 0$ & $£ 1,626$ & $£ 3,146$ & $£ 4,510$ & $£ 5,626$ & $£ 6,310$ & $£ 6,150$ & $£ 3,942$ & $-£ 5,840$ & $-£ 227,700$ \\
\hline & 2 & $£ 0$ & $£ 0$ & $£ 0$ & $£ 1,521$ & $£ 2,885$ & $£ 4,002$ & $£ 4,690$ & $£ 4,540$ & $£ 2,364$ & $-£ 7,233$ & $-£ 202,400$ \\
\hline & 3 & $£ 0$ & $£ 0$ & $£ 0$ & $£ 0$ & $£ 1,365$ & $£ 2,483$ & $£ 3,175$ & $£ 3,036$ & $£ 900$ & $-£ 8,475$ & $-£ 177,100$ \\
\hline & 4 & $£ 0$ & $£ 0$ & $£ 0$ & $£ 0$ & $£ 0$ & $£ 1,119$ & $£ 1,816$ & $£ 1,689$ & $-£ 400$ & $-£ 9,500$ & $-£ 151,800$ \\
\hline & 5 & $£ 0$ & $£ 0$ & $£ 0$ & $£ 0$ & $£ 0$ & $£ 0$ & $£ 700$ & $£ 587$ & $-£ 1,445$ & $-£ 10,200$ & $-£ 126,500$ \\
\hline & 6 & $£ 0$ & $£ 0$ & $£ 0$ & $£ 0$ & $£ 0$ & $£ 0$ & $£ 0$ & $-£ 100$ & $-£ 2,066$ & $-£ 10,380$ & $-£ 101,200$ \\
\hline & 7 & $£ 0$ & $£ 0$ & $£ 0$ & $£ 0$ & $£ 0$ & $£ 0$ & $£ 0$ & $£ 0$ & $-£ 1900$ & $-£ 9,650$ & $-£ 75,900$ \\
\hline & 8 & $£ 0$ & $£ 0$ & $£ 0$ & $£ 0$ & $£ 0$ & $£ 0$ & $£ 0$ & $£ 0$ & $£ 0$ & $-£ 7,100$ & $-£ 50,600$ \\
\hline & 9 & $£ 0$ & $£ 0$ & $£ 0$ & $£ 0$ & $£ 0$ & $£ 0$ & $£ 0$ & $£ 0$ & $£ 0$ & $£ 0$ & $-£ 25,300$ \\
\hline & 10 & $£ 0$ & $£ 0$ & $£ 0$ & $£ 0$ & $£ 0$ & $£ 0$ & $£ 0$ & $£ 0$ & $£ 0$ & $£ 0$ & $£ 0$ \\
\hline
\end{tabular}

$$
\operatorname{Att}_{i, j}=e^{\text {Benefit }_{i j}} .
$$

\subsection{The multiutility service companies}

A MUSCo can offer a household reduced utility costs while offering the same level of comfort as before, but with much greater resource use efficiency. In turn, a household must sign a contract with the firm. A MUSCo will assume responsibility for upgrading the insulation and installing high quality appliances that will reduce overall energy needs, and will simply charge the customers an additional sum per month. If a 10 year contract period is considered, then the calculations are the same as before, but now the MUSCo pays for the upgrading work instead of the household. Naturally, the MUSCo can undertake this work for considerably less cost than that which a private customer would pay. To attract customers to this new service, a MUSCo could choose to charge less for each unit of energy than the traditional utility suppliers. So, instead of the profit being simply $P_{\mathrm{e}}-C_{\mathrm{e}}$ (i.e., price of energy-cost of energy), a MUSCo could charge, for example, $\left(P_{\mathrm{e}}+C_{\mathrm{e}}\right) / 2$ to the customer and still make a profit on the supply as well as on the insulation and appliances it installs. For a customer, who moves from efficiency level $j$ to $i$ on signing a contract with a MUSCo, this means a reduced consumption and at the lower cost

\section{FIGURE 3}

(a)

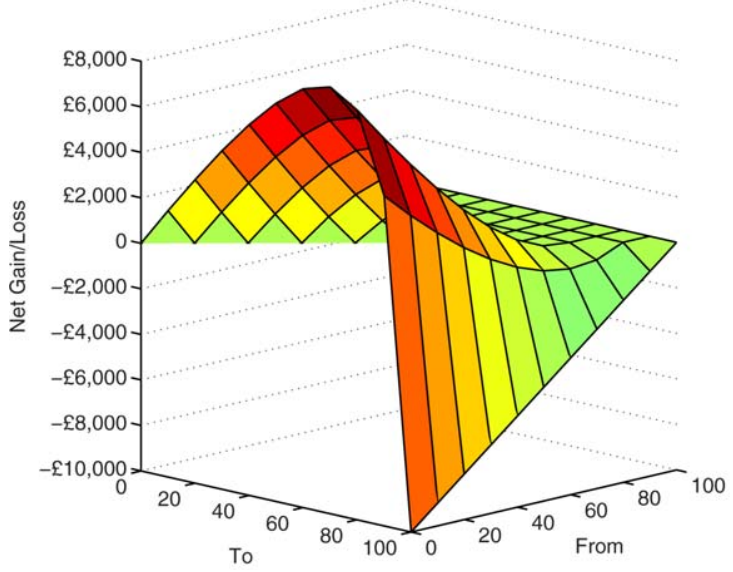

(b)

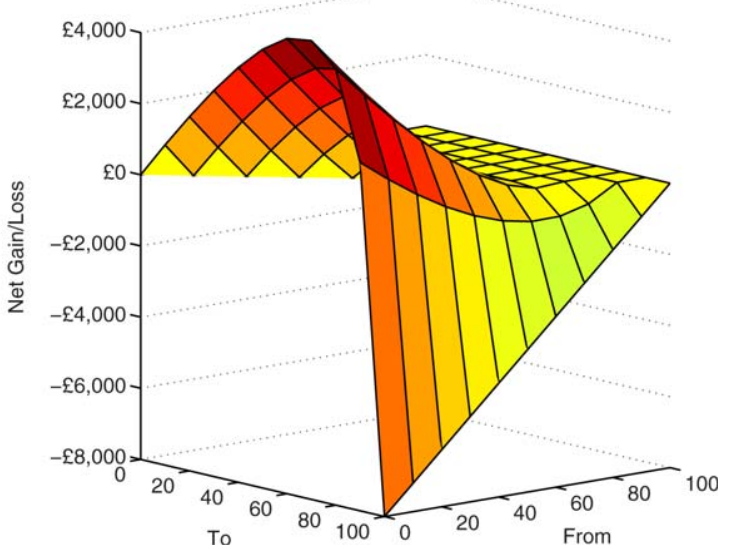

The net gain (over 10 years) for the action of increasing household energy efficiency from $j$ to $i$. (a) Annual energy costs of $£ 2000$, initial $10 \%$ upgrade costs of $£ 300$. (b) Annual energy costs of $£ 1200$, initial $10 \%$ upgrade costs of $£ 200$. 


\section{TABLE 3}

The Net Benefit of Improving Efficiency from Level $j$ to Level $i$ Through a MUSCo. Values Shown are for an Annual Energy Cost of $£ 2000$ and an Insulation/Appliance Cost of $£ 300$ for the First $10 \%$ Upgrade

\begin{tabular}{|c|c|c|c|c|c|c|c|c|c|c|c|c|}
\hline & & \multicolumn{11}{|c|}{$i$} \\
\hline & & 0 & 1 & 2 & 3 & 4 & 5 & 6 & 7 & 8 & 9 & 10 \\
\hline \multirow[t]{11}{*}{$j$} & 0 & $£ 0$ & $£ 2,240$ & $£ 3,928$ & $£ 5,542$ & $£ 7,046$ & $£ 8,376$ & $£ 9,403$ & $£ 9,834$ & $£ 8,820$ & $£ 2,414$ & $-£ 171,100$ \\
\hline & 1 & $£ 0$ & $£ 0$ & $£ 2,138$ & $£ 3,752$ & $£ 5,257$ & $£ 6,588$ & $£ 7,617$ & $£ 8,055$ & $£ 7,059$ & $£ 762$ & $-£ 153,990$ \\
\hline & 2 & $£ 0$ & $£ 0$ & $£ 0$ & $£ 2,014$ & $£ 3,520$ & $£ 4,851$ & $£ 5,883$ & $£ 6,328$ & $£ 5,355$ & $-£ 813$ & $-£ 136,880$ \\
\hline & 3 & $£ 0$ & $£ 0$ & $£ 0$ & $£ 0$ & $£ 1,855$ & $£ 3,188$ & $£ 4,223$ & $£ 4,675$ & $£ 3,730$ & $-£ 2,282$ & $-£ 119,770$ \\
\hline & 4 & $£ 0$ & $£ 0$ & $£ 0$ & $£ 0$ & $£ 0$ & $£ 1,633$ & $£ 2,671$ & $£ 3,132$ & $£ 2,220$ & $-£ 3,600$ & $-£ 102,660$ \\
\hline & 5 & $£ 0$ & $£ 0$ & $£ 0$ & $£ 0$ & $£ 0$ & $£ 0$ & $£ 1,290$ & $£ 1,761$ & $£ 888$ & $-£ 4,690$ & $-£ 85,550$ \\
\hline & 6 & $£ 0$ & $£ 0$ & $£ 0$ & $£ 0$ & $£ 0$ & $£ 0$ & $£ 0$ & $£ 680$ & $-£ 146$ & $-£ 5,416$ & $-£ 68,440$ \\
\hline & 7 & $£ 0$ & $£ 0$ & $£ 0$ & $£ 0$ & $£ 0$ & $£ 0$ & $£ 0$ & $£ 0$ & $-£ 630$ & $-£ 5,505$ & $-£ 51,330$ \\
\hline & 8 & $£ 0$ & $£ 0$ & $£ 0$ & $£ 0$ & $£ 0$ & $£ 0$ & $£ 0$ & $£ 0$ & $£ 0$ & $-£ 4,320$ & $-£ 34,220$ \\
\hline & 9 & $£ 0$ & $£ 0$ & $£ 0$ & $£ 0$ & $£ 0$ & $£ 0$ & $£ 0$ & $£ 0$ & $£ 0$ & $£ 0$ & $-£ 17,110$ \\
\hline & 10 & $£ 0$ & $£ 0$ & $£ 0$ & $£ 0$ & $£ 0$ & $£ 0$ & $£ 0$ & $£ 0$ & $£ 0$ & $£ 0$ & $£ 0$ \\
\hline
\end{tabular}

of $\left(P_{\mathrm{e}}+C_{\mathrm{e}}\right) / 2$ instead of $P_{\mathrm{e}}$. The charge must also incorporate the costs of improved insulation and appliances, to be distributed over the lifetime of the contract which, of course, the MUSCo could purchase in bulk at a reduced cost, and sell to the customer for $\operatorname{Ins}_{j, i}^{\text {mus }}=\delta \operatorname{Ins}_{j, i}$, where $\delta<1$. The net benefit for households signing up to a MUSCo can thus be written as

$$
\text { Benefit }_{i, j}^{\text {mus }}=P_{\mathrm{e}}(10-j)-\frac{P_{\mathrm{e}}+C_{\mathrm{e}}}{2}(10-i)-\mathrm{Ins}_{j, i}^{\mathrm{mus}},
$$

and it is assumed that MUSCos charge 30\% less for household upgrades, that is $\delta=0.7$, and a household's attraction to a MUSCo is calculated as

$$
\operatorname{Att}_{i, j}^{\text {mus }}=e^{\text {Benefit }_{i j}^{\text {mus }}} .
$$

This yields considerably more net return for a MUSCo household than those that remain independent, Table 3. It is implicitly assumed that the two MUSCo firms are equally attractive to customers, whereby they charge the same price for energy and household upgrades. Other strategies could be readily investigated by defining firmspecific attraction matrices.

\subsection{The Energy Efficiency Market}

Market dynamics are driven by households increasing efficiency, either independently or by signing up to a MUSCo that does it for them. By moving from a market where households independently choose and fit their own insulation and appliances, to a system where service companies take care of both energy supply and the insulation/ appliances in houses, we observe a market innovation that brings energy supply and demand together within a service market.

The initial distribution of households along the energy efficiency spectrum is shown in Figure 1. Now, consider, for example, efficiency level 4. Households in levels $j \in[0$, $1,2,3]$ can choose to upgrade to $i=4$ and, similarly, households in level $j=4$ can choose to upgrade to levels $i \in[5,6,7,8,9,10]$, Figure 4 . This upgrade can be done as either a noncontracted independent household, $H_{i}^{k=1}$, or as a contracted MUSCo household, $H_{i}^{k=2,3}$. The household populations at levels $i$ and $j$ change because either households at $j$ are "captured" by salespeople for traditional utility companies, denoted by $Y_{1}$, or by MUSCo salespeople, denoted by $Y_{2,3}$. This capture depends on the relative attractivity of $i$ as opposed to $j$, which is given by Eqs. (2) and (4). The model considers both independent customers and also customers that sign up to two distinct MUSCo firms, $M_{2}$ and $M_{3}$.

The 33 distinct household subpopulations, spread across 3 firms and 11 efficiency levels, will evolve in time due to interactions with salespeople. A generalized equation for the household dynamics can be written in the form

$$
\frac{\mathrm{d} H_{i}^{k}}{\mathrm{~d} t}=b H_{i}^{k}+\Delta^{+} H_{i}^{k}+\Delta^{-} H_{i}^{k}, \quad \text { for } \quad k=1,2,3,
$$

\section{FIGURE 4}

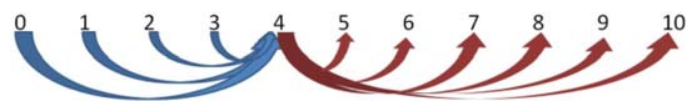

The household transitions into and out off efficiency level 4. 
where $b$ represents the growth rate of the household population due to construction, and is chosen to yield an approximate growth of $2.5 \%$ in housing stock over 10 years. The expressions $\Delta^{+} H_{i}^{k}$ and $\Delta^{-} H_{i}^{k}$ represent the increase and decrease, respectively, in each subpopulation due to sales. In order for a traditional utility provider to sign a customer (for at least a single model time step) there is little effort required. In contrast, each salesperson for a MUSCo, $Y_{2,3}$, could potentially take a longer time to get a household to sign up to a long term contract, as opposed to a single utility sale by $Y_{1}$. This "contact time" per household that sales staff expend on selling a contract is denoted by $\tau_{k}$, for $k \in[1,2,3]$. Various scenarios could be considered in which, for example, MUSCo sales take longer $\left(\tau_{1}<\tau_{2,3}\right)$ or MUSCo firms operate different sales strategies $\left(\tau_{2} \neq \tau_{3}\right)$. For simplicity, it is assumed that all firms contact time is identical, such that, $\tau_{k}=\tau=\Delta t, \forall k$ (i.e., one model time step). To express the change in customer numbers, due to the interaction of households and salespeople, the following general form is adopted

$$
\frac{c Y_{k} H^{k}}{1-c \tau H^{k}}
$$

where $c$ is the number of household contacts per salesperson per unit time, fixed at $c=2.5 \times 10^{-5}$. This expression incorporates the idea that for high numbers of potential customers, the rate of recruitment is approximately proportional to the number of salespeople available, but when potential customers are scarce, the rate depends primarily on the encounters between salespeople and customers. Equation (5) can be discretized to obtain

$$
\begin{aligned}
& H_{i}^{k}(t)=H_{i}^{k}(t-\Delta t)+\Delta t\left[b H_{i}^{k}+\Delta^{+} H_{i}^{k}+\Delta^{-} H_{i}^{k}\right]_{(t-\Delta t)} \text { for } \\
& \quad k=1,2,3 .
\end{aligned}
$$

In addition, bounding conditions are required to confine households to the 11 defined efficiency levels. For $k=1$ (i.e., independent households receiving utilities from traditional firms) we define, at any time $t$,

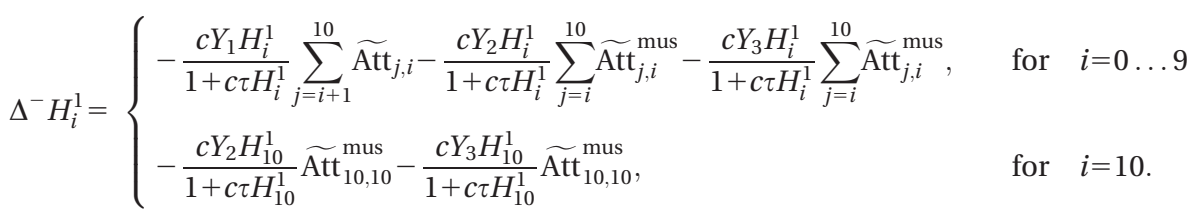

$$
\begin{aligned}
& \Delta^{+} H_{i}^{1}= \begin{cases}0, & \text { for } i=0 \\
\sum_{j=0}^{i-1} \frac{c Y_{1} H_{j}^{1}}{1+c \tau H_{j}^{1}} \widetilde{\mathrm{Att}}_{i, j}, & \text { for } i=1 \ldots 10\end{cases}
\end{aligned}
$$

where $\widetilde{\mathrm{Att}}$ and $\widetilde{\mathrm{Att}}{ }^{\text {mus }}$ represent the probabilities of independently upgrading household efficiency from level $i$ to level $j$ and switching to a MUSCo, respectively, which are readily calculated form the normalized attraction matrices,

$$
\widetilde{\mathrm{Att}}=\frac{\mathrm{Att}}{\sum_{i=0}^{10} \sum_{j=0}^{10} \mathrm{Att}_{i, j}} \quad \text { and } \quad \widetilde{\mathrm{Att}}{ }^{\mathrm{mus}}=\frac{\mathrm{Att}^{\mathrm{mus}}}{\sum_{i=0}^{10} \sum_{j=0}^{10} \mathrm{Att}_{i, j}^{\mathrm{mus}}} .
$$

Similarly, for $k \in[2,3]$ (i.e., households signed to MUSCo firms $M_{2}$ and $M_{3}$ ) we define, at any time $t$,

$$
\Delta^{-} H_{i}^{k}= \begin{cases}-\frac{c Y_{k} H_{i}^{k}}{1+c \tau H_{i}^{k}} \sum_{j=i+1}^{10} \widetilde{\operatorname{Att}_{j, i} \text { mus }} & \text { for } i=0 \ldots 9 \\ 0 & \text { for } \quad i=10 .\end{cases}
$$

$$
\begin{aligned}
& \Delta^{+} H_{i}^{k} \\
& = \begin{cases}\frac{c Y_{k} H_{0}^{1}}{1+c \tau H_{0}^{1}} \widetilde{\mathrm{Att}}_{0,0}^{\text {mus }}, & \text { for } i=0 \\
\sum_{j=0}^{i-1} \frac{c Y_{k} H_{j}^{k}}{1+c \tau H_{j}^{k}} \widetilde{\mathrm{Att}}_{i, j}^{\text {mus }}+\sum_{j=0}^{i} \frac{c Y_{k} H_{j}^{1}}{1+c \tau H_{j}^{1}} \widetilde{\mathrm{Att}}_{i, j}^{\text {mus }}, & \text { for } i=1 \ldots 10 .\end{cases}
\end{aligned}
$$

We, thus, calculate the net change in the number of households in each level of efficiency resulting from inflows from below and losses to above.

The ability of firms to sign potential customers is implicitly linked with the size of their respective sale forces. In reality, this would be a complex function of the internal economies and strategies of a firm. We adopt the assumption that the effort to sign new customers is affected by the number of potential customers, which are the independent uncontracted households $\sum_{i} H_{i}^{1}$. Thus, the sales staff will grow with the fraction of free households, and the staff numbers at time $t$ will be given by 


\section{TABLE 4}

The Revenues, Costs, and Profits of the UK's Six Largest Energy Companies [17]

\begin{tabular}{|c|c|c|c|c|c|}
\hline$£ /$ Customer/Year & 2009 & 2010 & 2011 & 2012 & 2013 \\
\hline Average revenue & $£ 1043$ & $£ 1063$ & $£ 1006$ & $£ 1174$ & $£ 1225$ \\
\hline Wholesale costs & $£ 621$ & $£ 588$ & $£ 537$ & $£ 612$ & $£ 628$ \\
\hline Other costs & $£ 291$ & $£ 288$ & $£ 294$ & $£ 354$ & $£ 392$ \\
\hline Supplier costs & $£ 123$ & $£ 152$ & $£ 146$ & $£ 154$ & $£ 157$ \\
\hline Profits & $£ 8$ & $£ 35$ & $£ 30$ & $£ 53$ & $£ 48$ \\
\hline
\end{tabular}

$$
Y_{k}(t)=Y_{k}(t-\Delta t)+\Delta t\left[\gamma_{k}\left(\frac{\sum_{i} H_{i}^{1}}{H_{\mathrm{tot}}}-0.1\right)\left(1-\frac{Y_{k}}{50,000}\right)\right]_{(t-\Delta t)}
$$$$
\text { for } k=1,2,3 \text {, }
$$

where a ceiling of 50,000 has been applied to the staff numbers, which grow at a rate of $\gamma_{k}$. Also, it is assumed that, when the population of independent households falls below $10 \%$ of the total housing stock, staff numbers are reduced to reflect the smaller pool of potential customers. Finally, it remains to determine how the price of energy affects household attractiveness to the different firms and efficiency levels. This is assumed to grow exponentially in time following

$$
P_{\mathrm{e}}(t)=P_{\mathrm{e}}(0) e^{\epsilon t}
$$

where $\epsilon$ is chosen to yield a $2 \%$ increase per annum in mean household energy costs and the initial price of energy in $2014, P_{\mathrm{e}}(0)$, is fixed at $£ 2000$ per annum.

\subsection{MUSCo Strategies}

Clearly, households profit by signing to a MUSCo but, of course, it is necessary that the MUSCos also make profits to successfully invade this new market of utility services. Firms' [Correction added on 3 August 2015, after first online publication: Firm's changed to Firms'] profits can be calculated for different strategies on energy price reduction and discounts on insulation costs. The operating profits of the United Kingdom's largest energy supply companies vary over time but appear to be approximately $5 \%$ at present, Table 4 . This implies that the difference between the price, $P_{\mathrm{e}}$, and the cost, $C_{\mathrm{e}}$, of energy would, in fact, be only $5 \%$. The MUSCo must, therefore, offer a monthly charge that is equivalent to a price between $95 \%$

\section{FIGURE 5}
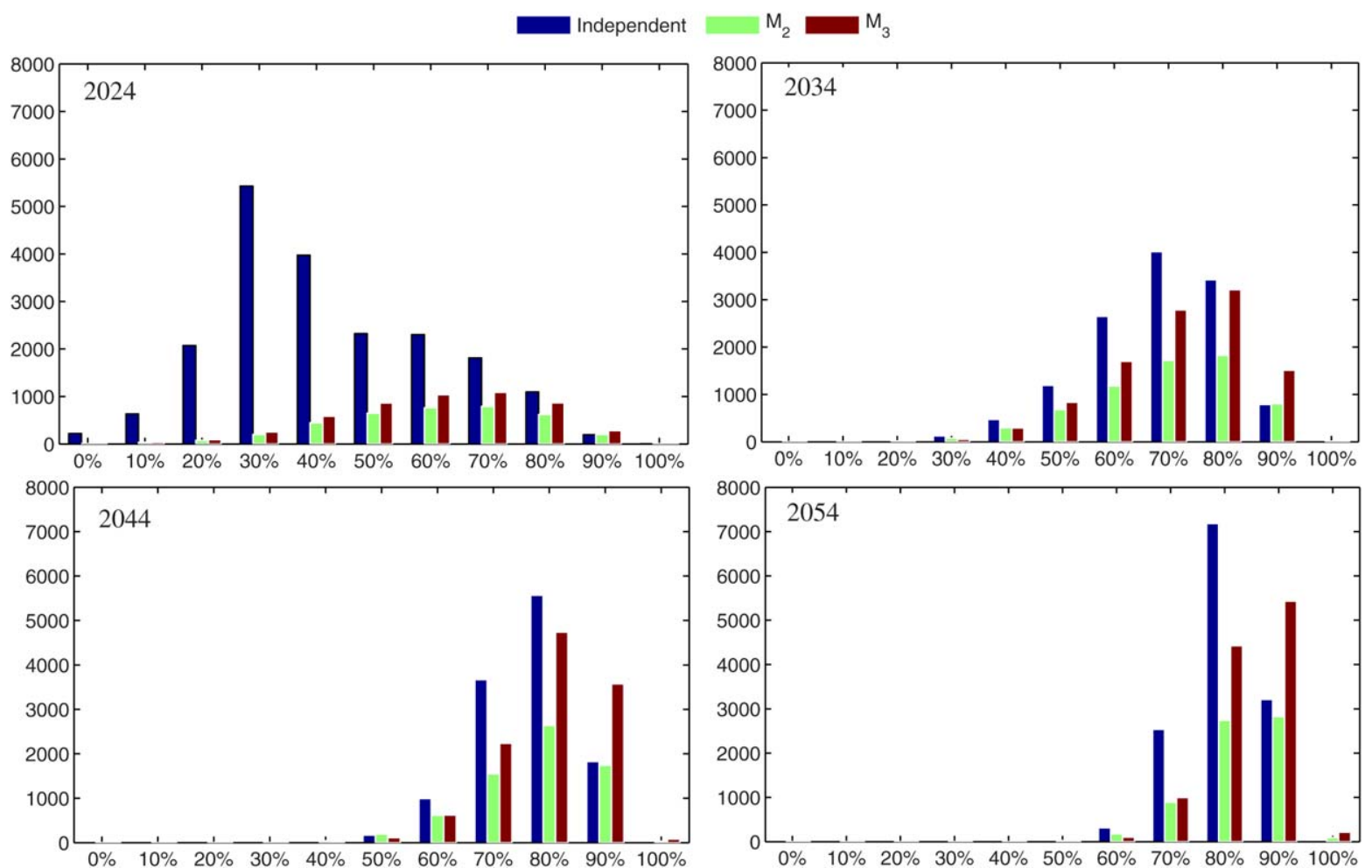

Energy efficiency distribution of households (in thousands) displayed at 10 year intervals. Results shown are calculated for an annual energy cost of $£ 2000$ and an insulation/appliance cost of $£ 550$ for the first $10 \%$ upgrade. 

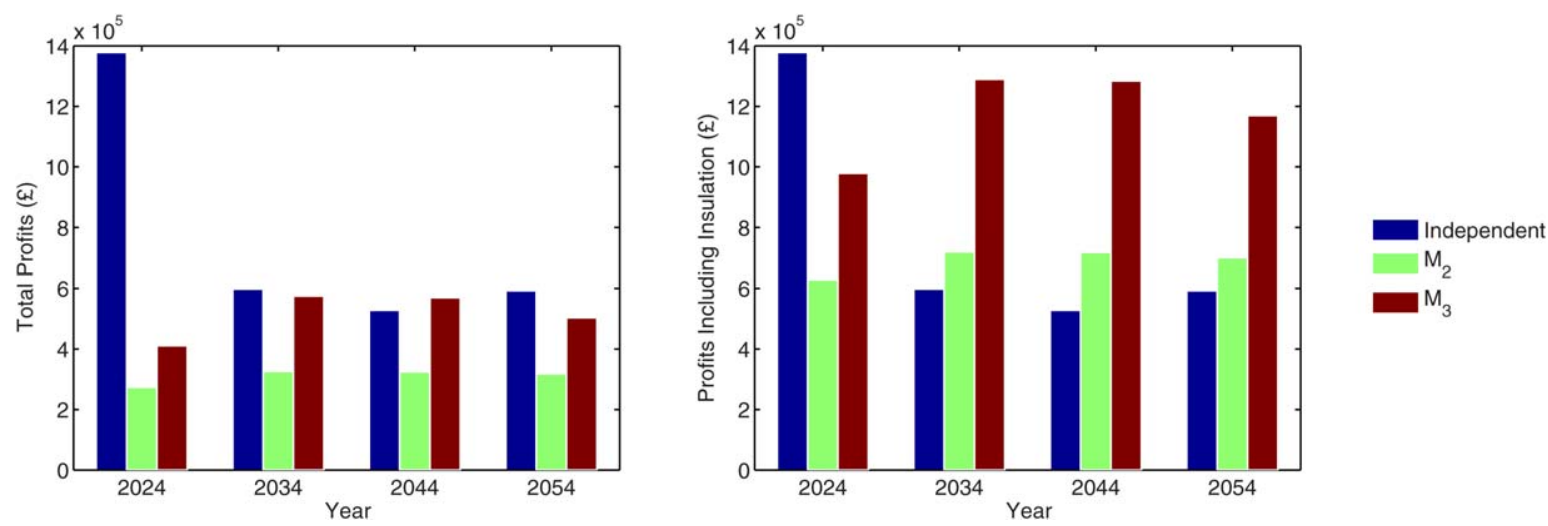

The profits made by the traditional utility firms and the MUSCos. Results shown are calculated for an annual energy cost of $£ 2000$ and an insulation/ appliance cost of $£ 550$ for the first $10 \%$ upgrade.

and $100 \%$ of the traditional providers, that is, $C_{\mathrm{e}}=0.95 P_{\mathrm{e}}$. Thus, the benefit for customers comes from the fact that the MUSCo can perform the upgrade at a discount and can buy efficient appliances in bulk. The profits made by the different suppliers over time can be readily calculated. For the traditional firm, it is the quantity of energy delivered multiplied by the difference between the cost and the price per unit, thus, the total profit made at time $t$ satisfies

$$
\operatorname{Pr}_{1}(t)=\operatorname{Pr}_{1}(t-\Delta t)+\Delta t\left[\left(P_{\mathrm{e}}-C_{\mathrm{e}}\right) \sum_{i=0}^{i=10}\left(1-\frac{i}{10}\right) H_{i}^{1}\right]_{(t-\Delta t)},
$$

For a MUSCo, the profit is determined from the monthly charge to its customers minus the cost of buying the energy. In addition, it is assumed that household efficiency upgrades would yield $10 \%$ of the cost as a profit to the MUSCo. This is the cost of improving the household efficiency from $j$ to $i$, which will be at a discount due to the scale of the activity. The charge needs only to reflect the cost of energy, plus a percentage profit on the cost of insulation/appliance upgrades. Thus, at any time $t$, the MUSCo profit will satisfy

$\operatorname{Pr}_{k}(t)=\operatorname{Pr}_{k}(t-\Delta t)+\Delta t\left[\left(\frac{P_{\mathrm{e}}+C_{\mathrm{e}}}{2}-C_{\mathrm{e}}\right)\left(1-\frac{i}{10}\right) \sum_{i=0}^{i=10} H_{i}^{k}+\operatorname{Pr}_{\mathrm{Ins}}^{k}\right]_{(t-\Delta t)}$

for $k=2,3$,

where, $\operatorname{Pr}_{\text {Ins }}^{k}$ represents the profit made from selling/installing more efficient insulation/appliances and is dependent on the number of new customers attained by a MUSCo in the time interval $\Delta t$,

$$
\operatorname{Pr}_{\text {Ins }}^{k}=0.1 \sum_{i=0}^{10} \sum_{j=0}^{i} \operatorname{Ins}_{j, i}^{\operatorname{mus}} \frac{c Y_{k}\left(H_{j}^{1}+H_{j}^{k}\right)}{1+c \tau H_{j}^{1}} \widetilde{\operatorname{Att}}_{i, j}^{\text {mus }}
$$

As profit is implicitly dependent on the sales force of a firm, which is adjusted at each time step following (6), we must also establish initial staff numbers and their growth rates over time, $\gamma_{k}$. As MUSCos are a newly emerging service in the model, it is assumed that their initial work force is considerably smaller than that of the traditional provider, such that $Y_{1}=500$ and $Y_{2,3}=200$. It is assumed that $M_{1}$ grows its sales capacity at the same rate as the traditional firm, $\gamma_{1}=\gamma_{2}=1.25$ per year, and $M_{3}$ grows at the faster rate of $\gamma_{3}=1.5$ per year.

\section{RESULTS}

The model is run over a time interval of 40 years from 2014 to 2054. The time-step, $\Delta t$, is chosen to yield 1000 iterations within this interval. The distribution of households moves from an average centred on $30 \%$ efficiency, Figure 1 , to an average centred on $80-90 \%$, Figure 5 . As the model runs forward in time, there are improvements in the efficiency distribution of households both as independent buyers of utilities, who pay for their own house improvements and there are also customers captured by the MUSCos, who are signed up for long term contracts. They choose this solution because of the reduced overall cost of energy and also the reduced cost of insulation and high quality appliances that a MUSCo can offer.

We see from Figures 6 and 7 that the profits available to MUSCos are potentially greater than those of traditional utility providers as a result of the additional profits made from the insulation and appliance improvement programme that they include. In essence, some 15 million households are going to need improved insulation and better appliances, so that the profits from these activities can be harvested by the MUSCos. Obviously, this is only a "temporary" situation in that it corresponds to a basic 


\section{FIGURE 7}

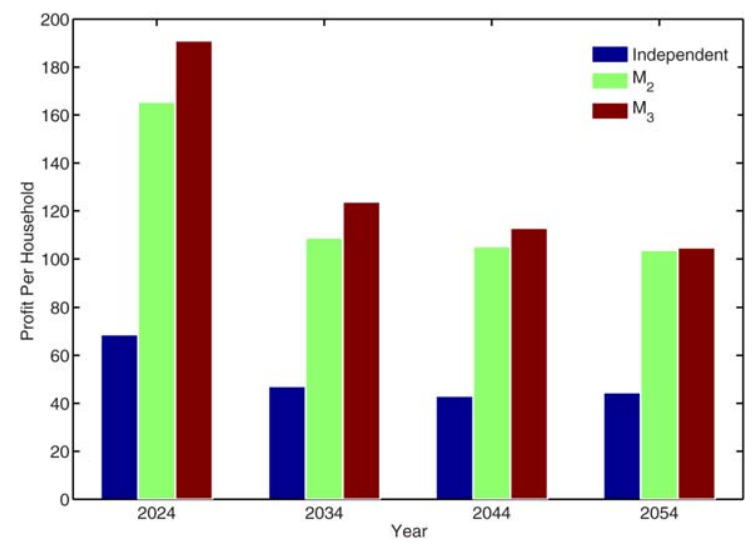

The profit per household made by the traditional utility firms and the MUSCos. Results shown are calculated for an annual energy cost of $£ 2000$ and an insulation/appliance cost of $£ 550$ for the first $10 \%$ upgrade.

improvement in thermal insulation and energy efficiency for UK housing, which once performed will inevitably need periodic renewal. Clearly, some of the profits that household improvement companies would have made in this UK wide energy efficiency improvement will now be included in MUSCo profits. For consumers, the attraction of MUSCos will be in their offering a service which means that consumers do not have to organize and self-finance household improvements.

Clearly, as energy demand decreases the traditional energy companies will inevitably have reduced turnover and profits. MUSCos, however, may be able to add services to the initial energy/utility service and use the long term relationships with customers to develop other areas of household management.

\section{DISCUSSION}

We have developed a systems dynamics model of the domestic energy demand and supply system in the United Kingdom. The model examines the potential for a new type of firm, the MUSCo, to enter the energy supply market. In essence, instead of just simply selling energy to households, the MUSCo proposes to manage the upgrading of existing insulation and domestic appliances to reduce household energy requirements, while maintaining the same comfort levels of the occupants. These energy services are offered under the terms of a long term contract where the household simply pays a regular monthly charge and the MUSCo supplies the energy, having raised the efficiency performance of the house to an agreed level. This action unites what are initially two separate tasks; (i) to supply energy, and (ii) to insulate and place high efficiency appliances in the house. As both of these actions are undertaken by the MUSCo, it would be possible to profit from both operations and, more importantly for the domestic consumer, to offer a cheaper route to energy efficiency than is possible by private self-financed improvements.

We considered a market scenario, where energy price rises over 40 years are assumed to be at an average of approximately $2 \%$ per year. This is not an unreasonable assumption and, of course, other possible scenarios could be easily explored. Household choice is modeled using an exponential function that translates the net gain/loss of a possible action into the number of households that choose that action. This functional form is commonly used to model consumer choice [16] and it adequately represents the idea that the household decision process will proceed by the most rewarding actions first, such that it becomes increasingly costly to make a given percentage increase in efficiency. Other functions could be used to incorporate additional issues such as the impact of neighborhood adoptions and economics of scale. However, the scope of this work is the average behavior of the population and, for our purposes, the exponential preference function provides a sufficient representation of the heterogeneous nature of the real system. Our model provides insight into how the energy services market could contribute to the reduction in greenhouse gas emissions due to reduced domestic energy consumption, which would aid the United Kingdom in meeting its 2050 target of at least an $80 \%$ reduction in emissions (from the 1990 baseline). Furthermore, the model could help MUSCo firms to explore different possible market strategies and the balance between immediate profits and the longer term success that may arise from faster expansion. Similarly, we could explore the advantages and disadvantages of different strategies in targeting sales teams according to specific household characteristics (e.g., ownership, occupancy, wealth, current state of insulation and appliance use, type of heating).

Of course in reality, the domestic energy demand would be changing because of several factors such as the acquisition of electric vehicles (and their consequent charging), and a switch perhaps from gas toward heat pumps. In addition to these ideas, instead of just modeling the demand side of households, we could also consider competing companies that would offer different possible "bundles" of services to households. The MUSCos could use different strategies such as different contractual lengths, different discount rates, and different profit margins. We could also potentially investigate the most favorable neighborhood for targeting by a MUSCo, and thus improve the success rate of a MUSCo. Such different types of competing business models and relevant policies, 
actions, and changing circumstances (subsidies, rising energy costs, etc.) could be explored and provide insight on the ways that the overall system can maintain comfort and convenience levels while greatly reducing carbon emissions, energy, and water consumption. The transition toward a "leasing" and "contracted service" type of operation can be modeled, as well as the long term consequences for design, maintenance, and overall efficiencies. The end of life resource recovery of leased products could also generate profits for the MUSCo. In many ways, we have moved toward a "life cycle analysis" of the whole sector to see how carbon emissions, energy, and resource efficiency can be improved in a sustainable way.

\section{ACKNOWLEDGMENTS}

This research was conducted as a part of the EPSRC funded project "Land of the MUSCos" (Grant number: EP/ J00555X/1). Enquiries for access to the data referred to in this article should be directed to researchdata@cranfield. ac.uk.

\section{REFERENCES}

1. Herring, H.; Roy, R. Technological innovation, energy efficient design and the rebound effect. Technovation 2007, 27, 194203.

2. RCEP. Energy - The Changing Climate; 22nd Report, The Stationery Office, London, 2000.

3. Palmer, J.; Cooper, I. United Kingdom housing energy fact file 2013. URN: 13D/276, DECC 2014.

4. Omer, A.M. Energy, environment and sustainable development. Renewable Sustainable Energy Rev 2008, 12, $2265-2300$.

5. Haszeldine, R.S. Carbon capture and storage: How green can black be? Science 2009, 325, 1647-1652.

6. Dresselhaus, M.S.; Thomas, I.L. Alternative energy technologies. Nature 2001, 414, 332-337.

7. Parnell, R.; Larsen, O.P. Informing the development of domestic energy efficiency initiatives: An everyday householdercentered. Environ Behav 2005, 37, 787-807.

8. Kellett, J. Community-based energy policy: A practical approach to carbon reduction. J Environ Plann Manag 2007, 50, 381396.

9. DECC. Energy Consumption in the UK 2014. Available at: https://www.gov.uk/government/uploads/system/uploads/attachment_data/file/337452/ecuk_chapter_1_overall_factsheet.pdf; (Accessed on November 23, 2014).

10. Department of Trade and Industry. UK energy sector indicators 2003: A supplement to the energy white paper Our energy future-Creating a low carbon economy. HMSO: London, 2003.

11. Milne, G.; Boardman, B. Making cold homes warmer: The effect of energy efficiency improvements in low-income homes: A report to the Energy Action Grants Agency Charitable Trust. Energy Policy 2000, 28, 411-424.

12. Bale, C.; McCullen, N.; Foxon, T.; Rucklidge, A.; Gale, W. Modeling diffusion of energy innovations on a heterogeneous social network and approaches to integration of real world data. Complexity 2014, 19, 83-94.

13. Robinson, M.; Varga L.; Allen, P. An agent-based model for energy service companies. Energy Conversion Manag 2015, 94, 233-244.

14. Jackson, T. Live better by consuming less? Is there a "Double Dividend" in sustainable consumption? J Ind Ecol 2008, 9, 1936.

15. SAP 2012. English housing survey 2012: energy efficiency of English housing report. The Government's Standard Assessment Procedure for Energy Rating of Dwellings. Available at: http://www.bre.co.uk/filelibrary/SAP/2012/SAP-2012_9-92.pdf.

16. Hanley, N.; Mourato, S.; Wright, R. Choice modelling approaches: A superior alternative for environmental valuatioin? J Econ Surv 2001, 15, 435-462.

17. OFGEM. The revenues, costs and profits of the large energy companies in 2013. Available at: https://www.ofgem.gov.uk/ ofgem-publications/90701/css2013summarydocument.pdf. Accessed on October 10, 2014. 